\title{
Assessment of Physiological Strain Due to Work and Exposure to Heat of Working Environments in Male Paddy Cultivators
}

\author{
Ayan Chatterjee, Surjani Chatterjee, Neepa Banerjee, Sandipan Chatterjee, Tanaya Santra, \\ Shankarashis Mukherjee*
}

Human Performance Analytics and Facilitation Unit, Department of Physiology, University Colleges of Science and Technology, University of Calcutta, Kolkata, India

\author{
Email address: \\ msasish@yahoo.co.in (S. Mukherjee)
}

\section{To cite this article:}

Ayan Chatterjee, Surjani Chatterjee, Neepa Banerjee, Sandipan Chatterjee, Tanaya Santra, Shankarashis Mukherjee. Assessment of Physiological Strain Due to Work and Exposure to Heat of Working Environments in Male Paddy Cultivators. Advances in Applied Physiology. Vol. 1, No. 1, 2016, pp. 8-11. doi: 10.11648/j.aap.20160101.12

\begin{abstract}
Introduction: Indian agricultural sector has been undergoing changes since 1950s. The record production of food grains from 50 million tons in 1950 to 241 million tons in 2009-10 is hailed as a breakthrough in Indian agriculture. However, agricultural sector in India is till date significantly dependent on non-mechanized techniques. An agricultural worker has to perform variety of tasks including ploughing, transplanting, threshing which require great physical effort. During the paddy cultivation, agricultural workers are engaged in the work field though out the day in different thermal conditions. Objective: A study has been carried out, in this backdrop, to assess the thermal environmental condition and effect of work and exposure to heat on physiological status in 31 male agricultural workers primarily engaged in transplanting of paddy seedlings tasks in southern area of West Bengal. Results and conclusion: The result of the study has indicated that environmental condition was above the recommended threshold value and the activities are strenuous as indicated from indicators of physiological strain.
\end{abstract}

Keywords: Agriculture, WBGT, Cardiovascular Strain Index, Transplanting

\section{Introduction}

Agriculture is the prime occupation in India, including in West Bengal and it accounts for about $13.9 \%$ of GDP. More than 60 per cent of total land area of the state has been used in agriculture and a large number of human resources including male and females are engaged in different types of agricultural tasks, of which paddy cultivation is most common [1-2]. Agricultural workers perform a variety of tasks throughout the year even in a day during the paddy cultivation [3]. Paddy cultivation involves in various tasks sowing of seeds, ploughing, transplantation, weeding, reaping, binding of straw, carrying of straw bundles, threshing and collection of crops: requiring substantial physical strength mostly performed by manual efforts [4]. Therefore the agricultural workers have to remain engaged in the field for almost $8-10$ hours per day throughout the year, exposed to different thermal conditions. It has been also observed that rise in ambient temperature is strenuous for the individuals, occupationally exposed to high temperature [58].In this backdrop, the present study has been undertaken to evaluate the effect of exposure to heat in the work environment in causing cardiovascular strain in male agricultural workers primarily engaged in transplanting of paddy seedlings tasks in district Hooghly in southern area of West Bengal.

\section{Methodology}

At first human resources engaged in paddy cultivation were approached for their preliminary consent for participation in the study, following ethical procedure. On obtaining the individual consent, the study was carried out on mutually convenient dates. 31 adult male individuals (age range 24 - 36 years) primarily engaged in transplanting of paddy seedlings, residing in and around the village Begampur, BlockChanditala II, District Hooghly (latitude $23^{\circ} 01^{\prime} \mathrm{N}$ to $22^{\circ} 39^{\prime} \mathrm{N}$ and longitude $88^{\circ} 30^{\prime} \mathrm{E}$ to $87^{\circ} 39^{\prime} \mathrm{E}$ ) and 
having a minimum working experience of four years and working for a period of at least 6 hours per day in the field, participated in the present study. Information about participants' age (year), working experience (year) and working time $\left(\mathrm{hr}^{-d a \mathrm{y}^{-1}}\right)$ wererecorded in a pre-designed schedule. Socio-economic status (SES) was assessedusing the updated Kuppuswamy's socio economic scale [9]. Air temperature $\left(\mathrm{T}_{\mathrm{a}}\right.$, or dry bulb temperature) $\left({ }^{\circ} \mathrm{C}\right)$, wet bulb $\left(\mathrm{T}_{\mathrm{WB}}\right)$ temperature $\left({ }^{\circ} \mathrm{C}\right)$, globe temperature $\left(\mathrm{T}_{\mathrm{g}}\right)$ and natural wet bulb temperature $\left(\mathrm{T}_{\mathrm{nwb}}\right)$ were noted during the working hours in the agriculture field [10]. The values of Wet bulb globe temperature (WBGT) $\left({ }^{\circ} \mathrm{C}\right)[10]$, corrected effective temperature (CET) $\left({ }^{\circ} \mathrm{C}\right)[11]$ and discomfort index (DI) $\left({ }^{\circ} \mathrm{C}\right)$ [12] were found out from temperature of dry bulb, wet bulb and globe thermometers.

Relative Humidity $(\mathrm{RH})$ of the working environment has been calculated. Physical and physiological parameters in terms of body height $(\mathrm{BH})(\mathrm{cm})$, nearest to $0.1 \mathrm{~cm}$, using an anthropometric rod and body weight $(\mathrm{BW})(\mathrm{kg})$ nearest to 0.1 $\mathrm{kg}$, using a pre calibrated weighing scale, with the participants without shoes and light clothing were measured. BMI was calculated from the measured body height and body weight of the individuals. Oral Temperature (OT) $\left({ }^{\circ} \mathrm{C}\right)$ of the participants was obtained at the beginning of the work. The pre work Heart Rate $\left(\mathrm{HR}_{\text {Pre work }}\right.$ ) (beats. $\left.\mathrm{min}^{-1}\right)$, systolic $\left(\mathrm{SBP}_{\text {Pre-work }}\right)$ and diastolic $\left(\mathrm{DBP}_{\text {Pre-work }}\right)$ blood pressure $(\mathrm{mm}$ $\mathrm{Hg}$ ) were recorded in the morning hours before the individuals started working. Physiological strain indicators Peak heart rate $\left(\mathrm{HR}_{\text {Peak }}\right)$ (beats. $\left.\mathrm{min}^{-1}\right)$ [13], estimated energy expenditure (EEE) $\left(\mathrm{kcal} . \mathrm{min}^{-1}\right)$ [14], net cardiac cost (NCC) [15] and cardio vascular strain index (CSI) [16] were found out following standard procedure.The environmental and cardiac response data were collected at regular intervals during morning (7-10 am), around noon (10:30 am - 1 pm) and afternoon $(2-5 \mathrm{pm})$ respectively, referred as first, second and third spell.

The obtained data have been presented in $\mathrm{AM} \pm \mathrm{SD}$ form. They were analyzed statistically andP value lower than 0.05 $(\mathrm{P}<0.05)$ was considered as significant.

\section{Results}

Basic characteristics including age (year), SES, working experience (year), average working time $\left(\mathrm{hr}^{-\mathrm{day}^{-1}}\right)_{\text {of }}$ the participants of the present study are presented in Table 1.

Table 1. Back ground information of the study participants.

\begin{tabular}{|c|c|}
\hline Variables & Values \\
\hline Age(year) & $26.6 \pm 5.69$ \\
\hline SES & Lower middle \\
\hline Working experience (year) & $7.6 \pm 3.61$ \\
\hline Working time(hr.day $\left.{ }^{-1}\right)$ & $7.1 \pm 1.15$ \\
\hline
\end{tabular}

The environmental condition adjudged by RH, WBGT, CET, and DI are presented in Table 2.
Table 2. Indicators of thermal environmental condition in three different spells.

\begin{tabular}{llll}
\hline $\begin{array}{l}\text { Indicators of thermal } \\
\text { environmental condition }\end{array}$ & Spell1 & Spell2 & Spell3 \\
\hline $\mathrm{RH}(\%)$ & $66.5 \pm 9.51$ & $55.9 \pm 8.05$ & $47.5 \pm 11.09$ \\
$\mathrm{WBGT}\left({ }^{\circ} \mathrm{C}\right)$ & $28.7 \pm 1.56$ & $33.9 \pm 1.87$ & $32.0 \pm 1.63$ \\
$\mathrm{CET}\left({ }^{\circ} \mathrm{C}\right)$ & $26.0 \pm 0.45$ & $31.5 \pm 1.28$ & $29.0 \pm 2.46$ \\
$\mathrm{DI}\left({ }^{\circ} \mathrm{C}\right)$ & $26.3 \pm 1.03$ & $34.3 \pm 2.15$ & $31.7 \pm 2.04$ \\
\hline
\end{tabular}

The physical and physiological variables are presented in Table 3 .

Table 3. Physical and physiological characteristics of the study participants.

\begin{tabular}{|c|c|}
\hline Variables & Values \\
\hline $\mathrm{BH}(\mathrm{cm})$ & $166.3 \pm 5.21$ \\
\hline $\mathrm{BW}(\mathrm{kg})$ & $64.2 \pm 9.71$ \\
\hline $\operatorname{BMI}\left(\mathrm{kg} \cdot \mathrm{m}^{-2}\right)$ & $20.9 \pm 2.88$ \\
\hline $\mathrm{OT}_{\text {Pre-work }}\left({ }^{\circ} \mathrm{C}\right)$ & $36.8 \pm 0.15$ \\
\hline $\mathrm{HR}_{\text {Pre-work }}\left(\right.$ beats.min $\left.{ }^{-1}\right)$ & $78.4 \pm 5.31$ \\
\hline $\mathrm{SBP}_{\text {Pre-work }}(\mathrm{mmHg})$ & $122.7 \pm 7.57$ \\
\hline $\mathrm{DBP}_{\text {Pre-work }}(\mathrm{mmHg})$ & $83.5 \pm 8.13$ \\
\hline
\end{tabular}

$\mathrm{AM} \pm \mathrm{SD}$.

In figure 1 the cardiac response profile in terms of $\mathrm{HR}_{\text {peak }}$ (beats.min ${ }^{-1}$ ) (a), EEE (kcal.min ${ }^{-1}$ ) (b) NCC (beats.min ${ }^{-1}$ ) (c), CSI (d) of the study participants has been presented.

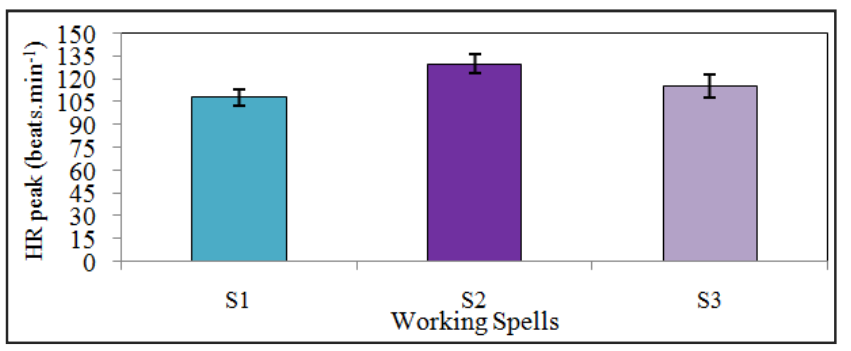

a) HR peak (beats. min-1) Profile of the study participants.

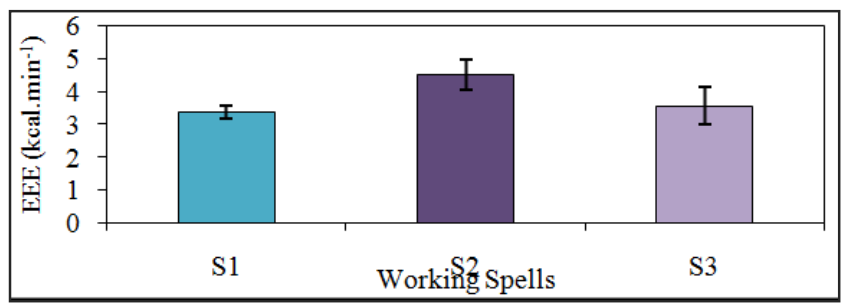

b) EEE (kcal. $\mathrm{min}^{-1}$ ) profile of the study participants.

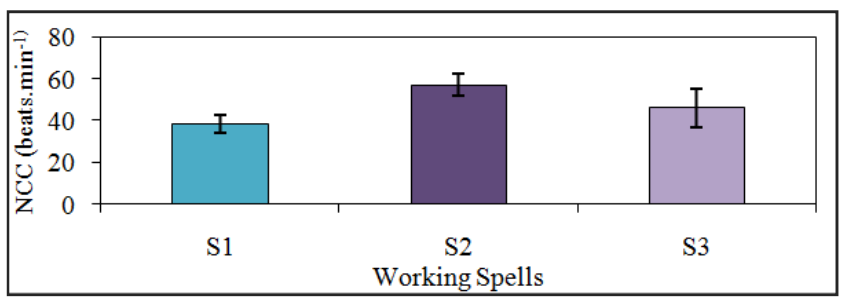

c) NCC (beats. $\min ^{-1}$ ) profile of the study participants. 


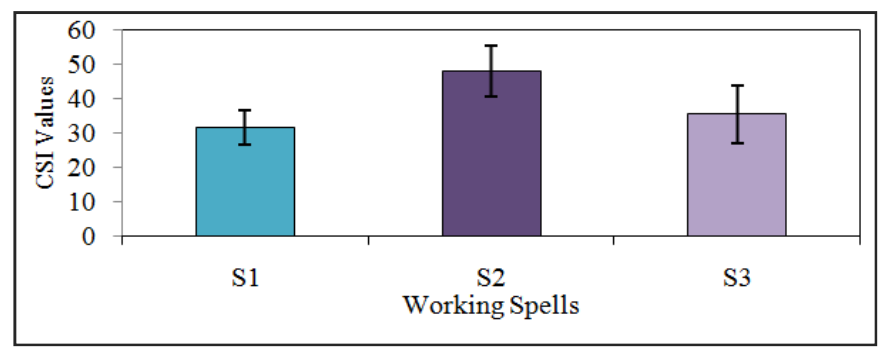

d) CSI profile of the study participants.

Fig. 1. Cardiac response profile of the study participants in terms of $H R_{\text {peak }}$ (beats.min ${ }^{-1}$ ) (a), EEE (kcal.min ${ }^{-1}$ ) (b), NCC (beats.min ${ }^{-1}$ ) (c), CSI (d).

\section{Discussions}

India is a tropical country with wide variation in climatic condition. In addition, the extreme weather events in India have geographical heterogeneity [10]. On the other hand, agriculture, one of the most important occupations of India, is largely dependent on the natural environmental conditions, mainly temperature and rainfall. Besides that, the agricultural activity involves manual woks in different phases of crop cultivation; and paddy cultivation is no exception to it.Transplanting of seedlings, one of the important tasks of paddy cultivation, is mainly carried out during rainy season. During the transplanting of paddy seedling task, physiological strain in terms of $\mathrm{HR}_{\text {Peak }}\left(\right.$ beats. $\min ^{-1}$ ), EEE $\left(\right.$ kcal.min ${ }^{-1}$ ), NCC (beats. $\mathrm{min}^{-1}$ ) and CSI of the male paddy cultivators, has been assessed. It has been observed from the present study that in the first, second and third spells of the working hours, the average values of $\mathrm{HR}_{\text {Peak, }}$, one of the most important indicators of physiological strain [17], varied from 107-112 beats. min $^{-1}, 125-129$ and $115-117$ beats. min $^{-1}$ respectively and thereby denoting 'moderate', 'heavy' and 'heavy' category of physiological strain [Fig. 1 (a)].The findings of the present study are in agreement with findings of earlier studies conducted on agriculture workers engaged in paddy cultivation [18-21]. EEE varied from 3.51-3.55 kcal.min ${ }^{-1}$ and $3.50-3.55 \mathrm{kcal}^{\mathrm{min}}{ }^{-1}$ in the first and third spell of the working hours respectively, indicating the work loads are in 'moderate' category; whereas in the second spell, the work is in 'heavy' category, as the EEE value is in range of

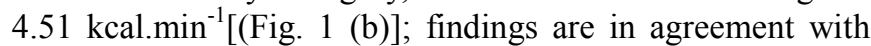
earlier reports[18-19].NCC (beats. min $^{-1}$ ) was found to vary from 37-39 beats. $\mathrm{min}^{-1}$ in first spell and indicating 'moderate' whereas at second and third spell it varied from 55.0-60.5 beats. $\mathrm{min}^{-1}$ and $45.0-49.0$ beats. $\mathrm{min}^{-1}$ respectively, indicating 'heavy' 'rather heavy' degree of physiological strain at second and third spells[(Fig. 1 (c)]. Similar trend of results has been observed in terms of CSI in the agricultural workers during second spell of the working hours. The magnitude of CSI was found to vary with the change of working spell. The environmental heat load might be one of the reasons for increased cardiovascular strain. On the other hand, thermal comfort condition of the environment is one of the major prerequisites for better performance of the individuals $[5,22-$ 26]. Thermal condition of the environment in the present study has been adjudged by some popular indicators like WBGT, CET and DI. In the first spell the average WBGT value has been found to be $28.7^{\circ} \mathrm{C}$ where up to $75 \%$ of the total working time is allowed; at second spell, the value of WBGT index has been found to be $33.9^{\circ} \mathrm{C}$, though no work is allowed [27-29] in this stage, human resources continue the work. Therefore, there is a risk of suffering from developing different degree of physiological strain in the agricultural workers. At third spell the average WBGT index value has been found to be $32.0^{\circ} \mathrm{C}$, where light category work only up to $25 \%$ of working hours is recommended. Continuation of work for long time in such adverse environmental condition may force agricultural workers for early termination of the work resulting deterioration of physical efficiency and decrease in work output.

It has been also found that in the present study the average CET values were $26.4^{\circ} \mathrm{C}, 31.5^{\circ} \mathrm{C}$ and $29.0^{\circ} \mathrm{C}$ respectively. At the first spell with average CET value being $26.4^{\circ} \mathrm{C}$, there is no restriction recommended against carrying out of the work. At second and third spell, only the 'light' category of work is permissible [11] as the average CET value has been found out to be $31.5^{\circ} \mathrm{C}$ and $29.0^{\circ} \mathrm{C}$. The human resources continue the tasks at second and third spell during the working hours therefore there is a risk of suffering from 'moderate' to 'heavy' degree of physiological stain during these spells. Another indicator of thermal environmental condition was DI. At the first spell average DI value has been found out to be $28.3^{\circ} \mathrm{C}$, indicating individual feel hot but physical work may be performed with minor difficulties. At second and third spell of the working hours with DI value $34.3^{\circ} \mathrm{C}$ and $32.0^{\circ} \mathrm{C}$, indicating this environmental exposure is 'stressful' to human resources and human resources performed their work with some difficulties [12] hence human resources performed their work with more difficulties. The environmental condition of the present study has been adjudged by three popular heat stress indices namely WBGT, CET and DI; however the values of these three indices are indicating similar environmental condition. This is further affirmed by significant positive correlation among these indices [WBGT and CET $(\mathrm{P}<0.05)$, WBGT and DI $(\mathrm{P}<$ $0.05)$, CET and DI $(\mathrm{P}<0.01)]$. From the result of the present study, it has been observed that the individuals working in the agricultural field would feel very hot and uncomfortable most of the day time, especially at around noon, i.e. during the spell 2. Moreover the magnitudes of physiological strain for the agricultural workers' were higher during the second spell compared to first and third spell.

\section{Conclusion}

From the present study, it may be concluded that unfavorable thermal environmental condition in working environment i.e. shift from the recommended threshold value, as adjudged in terms of select heat stress indices, is having negative health impacts on the agricultural workers involved in transplanting of paddy seedlings task as indicated by the physiological indicators. 


\section{Acknowledgement}

Authors are thankful to all volunteers for their participation.

\section{References}

[1] Statistics Related to Climate Change in India, Government of India, 2013

[2] Department of Agriculture and Cooperation Ministry of Agriculture Government of India, Annual report 2014 - 2015, pp. 1-178, 2015.

[3] S. Goswami, A. Pal, and P. C. Dhara, "Evaluation of work related musculoskeletal disorder andpostural stress among female cultivators engaged in post harvesting tasks," Indian Journal of Biological Science, vol. 18, pp. 16-25, 2012.

[4] S. K. Kar, and P. C. Dhara, "An evaluation of musculoskeletal disorder and socioeconomic status of farmers in West Bengal, India,” Nepal Med Coll J, vol. 9, pp. 245-249, 2007.

[5] S. Mukherjee, "Climate Change: Implications for human resources in informal sector of eastern India," In: Ergonomics for Rural Development (ISBN 978-93-5174-905-9), pp. 174 178, 2013.

[6] N. Banerjee, S. Chatterjee, A. Chatterjee, S. Chatterjee, S. Mitra, K. M. Agrawal, and S. Mukherjee, "Climate change: occupational health and performance implications for informal sector human resources," Managing Sustainable Development: Innovations and Best Practices, Springer (India), 2015.

[7] S. Mukherjee, "Occupational health scenario in unorganized sector in India: emerging issues," Proceedings of $100^{\text {th }}$ Indian Science Congress, pp. 123-124, 2013.

[8] S. Mukherjee, "Health implications of global warming: Warning for human resources in industries," Proceedings of $98^{\text {th }}$ Indian Science Congress, pp. 114, 2011.

[9] B. P. Ravi Kumar, S. R. Dudala, and A.R. Rao, "Kuppuswamy's socio-economic status scale - A revision of economic parameter for 2012," International Journal of Research and Development of Health, vol. 1, pp. 2-4, 2013.

[10] S. K. Dash, and T. Kjellstrom, "Workplace heat stress in the context of rising temperature in India," Current Science, vol. 101, pp. 496-503, 2011.

[11] R. Brake, and G. A. Bates, "Valid method for comparing rational and empirical heat stress indices," AnnOccup. Hyg., vol. 46, pp. 165-174, 2002.

[12] Y. Epstein, and D. Moran, "Thermal comfort and the heat stress indices," Industrial Health, vol. 44, pp. 388-398, 2006.

[13] A. Groborz, and T. Juliszewski, "Comparison of farmers workload by manual and mechanical tasks on family farms," Annals of Agricultural and Environmental Medicine, vol. 20, pp. 356-360, 2013.

[14] N. L. Ramanathan, S. R. Dutta, B. N. Roy, A. Chatterjee, and L. N. Mullick, "Energy cost of different muscular tests performed by Indian subjects," Indian Journal of Occupational
Health, vol. 10, pp. 253-261, 1967.

[15] A. Chamoux, A. M. Borel, and P. Catilina, "Pour la standardization d'unefrequencecardique de repos," Arch Mal Prof, vol. 46, pp. 241-250, 1985.

[16] D.G. Trites, D.G. Robinson, and E. W. Banister, "Cardiovascular and muscular strain during a tree planting season among British - Columbia silviculture workers," Ergonomics, vol. 36, pp. 935-949, 1993.

[17] P. O. Astrand, and K. Rodhal, Text book of Work Physiology (McGraw Hill, New York), 1986.

[18] P. Ojha, and S. Kwatra, "Analysis of different paddy transplanting methods in northern India: ergo - economical study," Journal of Applied and Natural Science, vol. 6, pp. 654-658, 2014.

[19] S. Pradhan, and S. K. Mohanty, "Ergo-economical analysis of different paddy transplanting operations in eastern India," Journal of Agriculture and Veterinary Science, vol. 6, pp. 23$27,2014$.

[20] B. Sam, "Ergonomic evaluation of conoweeder for wet land paddy," IJSR, vol. 4, pp. 2818- 2822, 2015.

[21] D. Jena, and S.K. Mohanty, "Circulo - respiratory efficiency of agricultural workers in Odisha, India," International journal of scientific \& technology research, vol. 3, pp. 265-269, 2014.

[22] T. Kjellstorm, I. Holmer, and B. Lemke, "Workplace heat stress, health and productivity- an increasing challenge for low and middle-income countries during climate changes," Heat, work and health: Implications of Climate Change, pp. 1-6, 2009.

[23] N. Banerjee, S. Chatterjee, T. Santra, and S. Mukherjee, "Significance of thermal comfort standard for Indian urban household: A review," Impact of Pollution: Assessment and Awareness, (ISBN 978-81-921083-8-4), pp. 147-151, 2014.

[24] T. Santra, S. Chatterjee, N. Banerjee, and S. Mukherjee, "Global Warming: Impact on human health, Impact of Pollution: Assessment and Awareness, (ISBN 978-81-9210838-4), pp. 113-119, 2014.

[25] S. Chatterjee, S. Chatterjee, N. Banerjee,A. Chatterjee, S. Mitra, K.M. Agrawal, and S. Mukherjee, "Management strategies for water scarcity in urban areas in the context of climate change," Proceedings of IWWA $47^{\text {th }}$ Annual Convention, pp. 352, 2015.

[26] K. Parsons, "Human thermal environments: the effects of hot, moderate and cold temperatures on human health, comfort and performance", 2nd Ed., Taylor \& Francis. London, 2003.

[27] ACGIH, "Threshold limit values and biological exposure indices," Cincinnati, Ohio, 2008.

[28] American Industrial Hygiene Association, "Ergonomic guide to assessment of metabolic and cardiac costs of physical work," American Industrial Hygiene Association Journal, vol. 32, pp. 560, 1971.

[29] World Health Organization, "Health factors involved in working under conditions of heat stress: Report of a WHO scientific group", WHO technical report series, pp. 412, 1969. 